\title{
Micro-learning in College English Teaching
}

\author{
Jiaying Meng1, a , Zhifan Wang', b \\ ${ }^{1}$ Teaching and Research Institute of Foreign Languages, Bohai University, Jinzhou121013, China; \\ ${ }^{2}$ Harbin Flying Academy, Harbin150006, China. \\ amengjiaying1@163.com, bwzf402@163.com
}

\begin{abstract}
With the advance of mobile communications technology and the spread of smart phones and tablet PCs, learning forms have changed dramatically. As a new form of learning, micro-learning is welcomed by many teachers and learners. Micro-learning, also known as the fragmented learning, is different from traditional systematic learning method. With this learning form, learners' learning activities are not confined by time and place; they can study anytime, anywhere with relatively small learning units for a short time. The goal of college English teaching is to develop students' comprehensive ability of English, including listening, speaking, reading and writing, as well as autonomous learning ability. Applying micro-learning in the teaching of college English is of great benefit. This thesis introduces the research and development of micro-learning and suggests concrete ways to conduct micro-learning in the teaching of college English.
\end{abstract}

Keywords: micro-learning; college English teaching; mobile devices; autonomous learning.

\section{Introduction}

In recent years, with the rapid development of information technology, digital technology and the mobile communications technology, a variety of intelligent mobile terminals, such as smart phones and tablet PCs, become more popular than before. Being portable, convenient and of small size, these mobile devices have become an indispensible part of people's life. The progress of technology promotes the transformation of learning style, and there appears a kind of learning method in the learning area, that is micro-learning.

Micro-learning, also known as the fragmented learning, is different from traditional systematic learning method. With this learning form, learners' learning activities are not confined by time and place; they can study anytime, anywhere with relatively small learning units for a short time. [1]As a new form of learning, micro-learning has the characteristics of convenience and flexibility and are welcomed by more teachers and learners.

Micro-learning plays a positive role in achieving the goal of college English teaching which aims to develop students' comprehensive ability of English, including listening, speaking, reading and writing, as well as autonomous learning ability.

English learning covers more than a wide range of content including listening, reading, writing, translation and oral English But in the current situation of college English teaching, fewer teaching periods and large class size make it difficult to meet students' learning needs. So the time after class is the key time for students to learn English. How to make better use of the spare time to make effective English learning has become a very important issue. On the one hand, many students have poor autonomous learning ability, without teachers' supervision and guidance, they do not know what to learn; on the other hand, there are many professional courses and various activities at college, for most students it is difficult to spend a lot of time learning English. Therefore, it has become a powerful way to improve students' English ability and interests by making full use of the students' fragmented time through micro-learning.

This thesis firstly introduces the research and development of micro-learning; secondly it puts forward concrete ways to apply micro-learning in college English teaching and finally sums up the benefit of conducting micro-learning in college English teaching. 


\section{Development of Micro-learning}

Since the twenty-first century, the world has gradually entered the information era; the field of education technology has also been a great change. Although the traditional mode of education still plays a role that cannot be replaced, the intelligent mobile devices such as the smart phones provide a new learning channel through which people's learning patterns are changing.

In 2004, an Austrian study expert, Martin Lindner, first puts forward the concept of micro-learning and describes it as a new type of learning based on micro-content and micro-media [2]. In 2005, Australia's Innsbruck University hosted the first International Symposium on micro-learning, and then the seminar is held once a year. The United States is also actively studying the role of microlearning. In Purdue University, Stanford University, Duke University, teachers provide students with teaching material on the Internet; students can download it with mobile phones at any time.

In China, the research of micro-learning is still in its early stage, and it has been paid more and more attention by experts and scholars in recent years. Renowned scholar Professor Zhu Zhiting describes the features of micro-learning as "micro, small, light and fast" [3]; Professor Gu Xiaoqing in East China Normal University conducted in-depth researches on micro-learning from the perspective of lifelong learning. These research results have laid a foundation for the study and development of micro-learning in China.

\section{Application of Micro-learning in College English Teaching}

The content of collage English teaching covers English listening, grammar, vocabulary, reading and writing, etc. It is of great importance to conduct micro-learning with proper learning content and to design effective learning activities.

\subsection{Choosing Proper Learning Content for Micro-learning}

The content of micro-learning has to be with reasonable amount of information and with prominent key points. Due to the limitations of mobile devices, the selection and presentation of learning content is different from the traditional teaching content. The selection of the content should be concise, focused, and should not choose long paragraphs as the learning content. [4] At present, there are a large number of applications for Android systems or apple IOS system in the mobile phone software market which are available for learners to download. The design of these applications is more mature, and suitable for students to conduct autonomous micro-learning.

According to different functions, the software for English learning can be classified as multifunctional software and sole-functional software. The former covers many aspects of English learning such as listening, reading, writing and speaking, etc. combing words, pictures, and videos and multimedia together; the latter focuses on just one aspect of English learning with more detailed information about certain aspects in English learning. In addition to the software on the Internet, teachers can also design their own software for micro-learning. Such software often takes students' different characteristics and learning requirement into account and can yield better learning effect.

\subsection{Designing Reasonable Activities for Micro-learning}

The micro-learning of college English with mobile devices can enhance communication and interaction between teachers and students. Students can arrange their own time and place to learn English, which greatly improve the students' learning interest and efficiency. This new learning form will change the concept of college students' English learning, and develop a new field for English learning. As is shown in Figure 1, teachers can arrange the specific learning activities in this mode.

This learning mode has many advantages. Firstly, the learning equipment is convenient and portable. With smart mobile phones and the tablet PCs, students can make good use of their fragmented spare time to learn English, breaking the limitations of time and place; secondly, the learning content is abundant. Students can have access to a large amount of useful information about English learning with pictures, videos, audios and other multimedia forms. The rich content and vivid presentation of knowledge can greatly improve students' interest in learning English; thirdly, the 
interaction is timely and effective which can enhance students' participation in the process of learning.

The smart phones and other mobile devices have a strong ability to transmit data, to lay the foundation for the timely and efficient interaction. Through these mobile devices, students can exchange their different ideas, share their learning experience and they can also turn to their teachers for help through the mobile devices. In the meanwhile, teachers can give students guidance and help timely, and supervise their learning process.

Last but not the least, the multiple supervision can ensure an effective leaning result. Learning supervision in the micro-learning process consists of two aspects. One is supervision for the courseware learning and the other is the assessment for the learning results. Students have to pass some tests in order to move to a new part of the courseware and their learning time and speed will be recorded. To evaluate the learning effect, teachers can provide a comprehensive test including vocabulary, writing, listening, etc. In addition, they can also be set to allow students to conduct self-assessment and mutual evaluation. [5]Through multiple learning monitoring, teachers can effectively adjust the students' learning progress and to help students grasp the knowledge points.

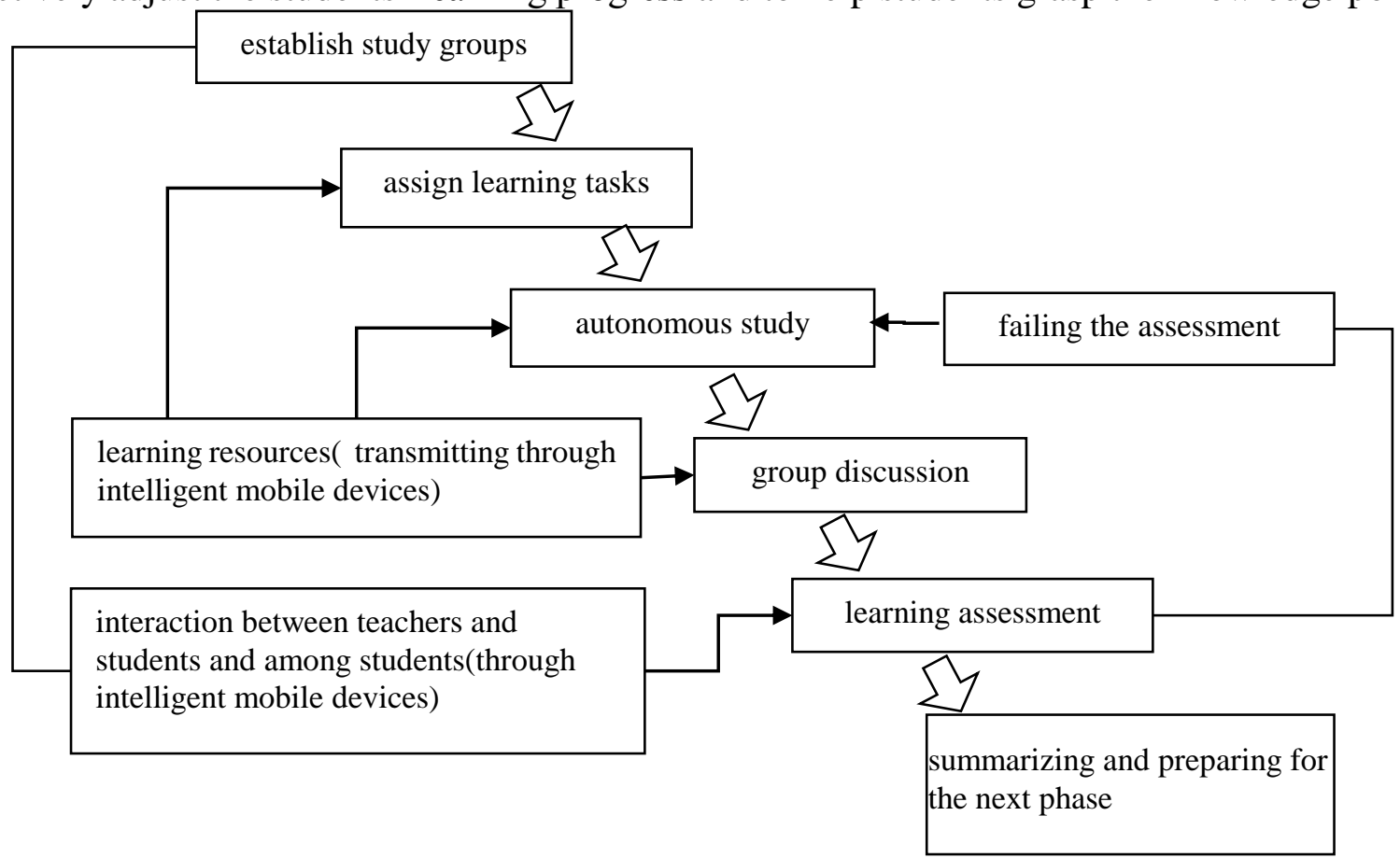

Fig.1 Design of micro-learning activities

\section{Summary}

Through micro-learning, students' time in preparation before class and review after class has increased and they are more active in class activities. Micro-learning provides different students with personalized learning channels and meet their different learning needs and improve their learning efficiency and learning effect. Micro-learning is proved to be a very effective way to improve students' autonomous learning ability and cultivate the fun of learning English. It is not the negation of the traditional teaching mode; on the contrary, it is a beneficial supplement to the traditional teaching mode. Micro-learning, as a new learning model, has shown its great potential. With the development of technology and people's acceptance, micro-learning will play a greater role in the future of college English teaching. 


\section{References}

[1] Martin Lindner, Peter A. Bruck. Micromedia and Corporate Learning: Proceedings of the 3rd International Microlearning 2007 Conference [M]. Innsbruck: Innsbruck University Press, 2007,p.52-55

[2] Information on: https://en.wikipedia.org/wiki/Microlearning

[3] [3]. Zhu Zhiting. Report on the Foresightful Research of Educational Technology [J].E-education Research, (2012) No.4, p.5-14.

[4] [4]. Zhang Hongling, Zhuye, Sun Guifang, et al. Web-Based Foreign Language Teaching: Theories and Designing [M]. Shanghai: Shanghai Foreign Language Education Press, 2000, p.67-80.

[5] [5]. Mcnamara M J, Deane D. Self-Assessment Activities: Toward Language Autonomy in Language Learning [J]. Tesol Journal, (1994) No.5, p.17-21. 